INRA Prod. Anim.,

2013, 26 (4), 363-374

\title{
La viande du futur sera-t-elle produite in vitro ?
}

\author{
J.-F. HOCQUETTE ${ }^{1,2}$, P. MAINSANT ${ }^{3}$, J.-D. DAUDIN ${ }^{4}$, I. CASSAR-MALEK ${ }^{1,2}$, D. REMOND ${ }^{5,6}$, M. DOREAU ${ }^{1,2}$, \\ P. SANS ${ }^{1,8}$, D. BAUCHART ${ }^{1,2}$, J. AGABRIEL ${ }^{1,2}$, W. VERBEKE ${ }^{9}$, B. PICARD ${ }^{1,2}$ \\ 1 INRA, UMR1213 Herbivores, F-63122 Saint-Genès-Champanelle, France \\ 2 Clermont Université, VetAgro Sup, UMR1213 Herbivores, BP 10448, F-63000 Clermont-Ferrand, France \\ 3 Académie de la Viande, 149 rue de Bercy, 75012 Paris, France \\ ${ }^{4}$ INRA, UR0370 QuaPA, F-63122 Saint-Genès-Champanelle, France \\ ${ }_{5}^{5}$ INRA, UMR1019, Nutrition Humaine, CRNH Auvergne, 63000 Clermont-Ferrand, France \\ ${ }^{6}$ Clermont Université, Université d'Auvergne, UMR1019, Nutrition Humaine, \\ BP 10448, F-63000 Clermont-Ferrand, France \\ 7 INP-ENV Toulouse, 23 chemin des Capelles, 31076 Toulouse Cedex 3, France \\ 8 INRA, UR1303 ALISS, 65 boulevard de Brandebourg, 94205 Ivry-sur-Seine, France \\ ${ }^{9}$ Ghent University, Department of Agricultural Economics, Coupure Links 653, B-9000 Ghent, Belgium
} Courriel : jean-francois.hocquette@clermont.inra.fr

L'élevage et la filière viande sont l'objet de questionnements importants pour répondre aux attentes sociétales (bien-être animal, protection de l'environnement, réduction de la faim dans le monde). Plusieurs approches sont possibles pour relever ces défis, entre autres la production de viande artificielle qui présente toutefois de fortes limitations techniques, économiques et sociales.

L'idée de proposer aux consommateurs des steaks artificiels n'est pas nouvelle ${ }^{1}$. Avec des succès divers, on a élaboré dans le passé des viandes hachées enrichies en protéines végétales, des steaks de protéines végétales et également des steaks de protéines " de pétrole ». Un nouveau projet, révélé par les médias dès 2010, se développe, principalement aux Pays-Bas et aux Etats-Unis, pour produire artificiellement de la viande en laboratoire. Les acteurs de ce projet sont regroupés dans un consortium international, leur donnant une certaine visibilité. L'objectif est de produire un succédané de viande sans passer par l'élevage, l'abattage et la découpe. La motivation est de réduire les inconvénients, réels ou supposés, attribués à l'élevage en le réduisant, voire en le supprimant.

Comment en est-on arrivé à l'idée de supprimer l'élevage? En effet, après 2,5 millions d'années de chasses périlleuses et de cueillettes hasardeuses, il y a 10000 ans environ, l'humanité a inventé l'agriculture et l'élevage. Ces innovations lui ont permis de se nourrir plus facilement et plus convenablement libérant ainsi du temps pour se consacrer aux progrès technologiques, dont font partie les progrès médicaux récents. Ainsi, en dix millénaires, l'humanité est passée de quelques millions de personnes à sept milliards.

Malgré ces succès, la progression de la production agricole, notamment de l'élevage, est désormais aussi considérée comme une menace pour la planète et pour l'humanité. Les critiques se sont cristallisées sur quelques thèmes :

- le droit de tuer des animaux pour les manger : c'est la question la plus radicale posée par le courant de pensée végétarien à laquelle tente de répondre la fabrication de succédanés de viande ;

- le bien-être animal dans les élevages modernisés : la notion «d'élevage industriel » est invoquée pour qualifier les méthodes d'élevage intensif accusées, à tort ou à raison, d'induire un certain mal-être des animaux domestiques ;

- la dégradation de l'environnement par l'élevage : il s'agit entre autres de la production des gaz à effet de serre par les élevages de ruminants et de la consommation d'énergie et d'eau notamment par les effluents d'élevage. Les nitrates contenus dans ces derniers permettent depuis toujours de fertiliser les sols agricoles mais une concentration excessive pose problème ;

- la faim dans le monde : " l'élevage industriel » nourrit avec des céréales et des oléo-protéagineux les animaux en totalité (porcs et volailles) ou en partie (ruminants). Ceci, avec la croissance démographique, entrâ̂nerait une concurrence accrue entre l'Homme et l'animal pour l'utilisation des ressources alimentaires végétales.

Récemment dans les pays occidentaux, ces critiques ont été largement reprises par les courants de pensée prônant le végétarisme ou le végétalisme. Le projet de viande de culture vise à réduire les inconvénients réels ou supposés de l'élevage, tout en préservant la possibilité de consommer des produits carnés naturels ou artificiels. En effet, une part importante de l'humanité est attachée à une alimentation omnivore, donc partiellement carnivore, et nous admettrons que la « viande artificielle », s'inscrit dans la partie carnivore de l'alimentation humaine.

\footnotetext{
1 En 1932, Winston Churchill dans son livre « Thoughts adventures » écrivait : « Dans cinquante ans, nous échapperons à l'absurdité d'élever un poulet entier afin de manger le pectoral ou l'aile, en cultivant ces pièces séparément dans un milieu approprié... ».
} 
La première partie de cet article relate les expériences antérieures de substitution des protéines animales avant d'examiner les principes scientifiques et techniques de production de la viande artificielle. Puis, nous expliciterons les intérêts et les limites de la viande artificielle par rapport à des problématiques liées à la nutrition humaine, aux pratiques modernes de l'élevage, et aux comportements des consommateurs. Enfin, nous évoquerons les différentes alternatives pour répondre aux enjeux du futur.

\section{1 / Les expériences de substitution des protéines animales}

\section{1 / Historique de la substitution des protéines animales par des protéines végétales}

L'Homme consomme des protéines végétales depuis toujours, principalement en mangeant des légumineuses mais aussi du pain et des fruits. L'idée de fabriquer des analogues de viande à partir de protéines végétales plus ou moins texturées a émergé au début des années 1960 dans les pays occidentaux. Au-delà de raisons religieuses ou philosophiques marginales, il y avait, comme aujourd'hui, la crainte que l'élevage ne puisse faire face à la demande croissante en protéines de la population. De nombreux travaux ont été conduits pendant 30 ans sur la substitution des protéines animales par les protéines végétales et Godon (1996) en a fait une synthèse très complète. La question est remise à l'ordre du jour du fait de la demande mondiale croissante de viande et des problèmes environnementaux posés par l'élevage intensif d'animaux nourris avec des plantes protéagineuses (Asgar et al 2010).

La texturation d'extraits protéiques de plantes protéagineuses est une idée nouvelle dans les pays occidentaux, mais ancestrale en Asie. De nombreux produits dérivés du soja, subissant une éventuelle fermentation, sont en effet consommés couramment sur ce continent à tradition végétarienne. Ils consistent en de simples produits liquides (lait et sauce de soja), mais aussi en des produits ayant une texture solide ( miso », « tempeh », «tofu »). Les premiers ne nécessitent qu'une étape d'extraction par broyageséparation en milieu liquide suivie d'un traitement thermique permettant d'inactiver certaines enzymes et facteurs antinutritionnels. Le tofu, produit emblématique, peut être considéré comme un analogue de la viande. Il requiert de concentrer les protéines extraites et de provoquer leur coagulation par ajout de chlorures et de sulfates de calcium ou de magnésium et/ou par acidification. Le tofu est un produit peu aromatique, cuit comme de la viande et intégré dans des mets variés accompagnés de divers végétaux et épices apportant la flaveur.

\section{2 / Travaux de recherche pour mieux valoriser les protéines végétales}

Des travaux de recherches depuis les années 1960 ont eu pour but de proposer des solutions techniques pour valoriser les protéines issues des oléo-protéagineux, en particulier du soja, du colza, du tournesol, du pois, du lupin et de la féverole. L'enjeu est de créer des structures solides organisées, ayant une teneur en protéines supérieure à $15 \%$. Dans presque tous les cas, ils sont incorporés à des produits carnés sous forme de poudre ou de granulés et l'on parle alors de " produits enrichis en protéines », le but principal étant de réduire le coût et/ou de contrôler la texture. Dans quelques cas, il s'agit de proposer un analogue de viande, ou substitut, pouvant être cuisiné comme de la viande et ayant des propriétés organoleptiques proches. Purwanti et al (2010) ont fait le point des technologies disponibles. Même si la microfluidique ouvre des possibilités nouvelles pour exploiter les connaissances relatives aux propriétés des protéines dans le but de les texturer, seules deux grandes technologies ont été testées pour mettre en forme les solutions protéiques extraites de ces végétaux : la cuisson-extrusion et le filage.

La cuisson extrusion est maintenant très répandue, d'un coût acceptable et permet de structurer des pâtes d'amidon et/ou de protéines. La pâte visqueuse chauffée sous pression dans une enceinte est poussée en continu par une ou deux vis sans fin au travers d'une filière (plaque percée de trous). En sortie de filière, la pâte cuite subit une expansion rapide. La texture peut être partiellement contrôlée en jouant sur le profil de température, le niveau de pression et le type de filière. C'est la technique de choix pour fabriquer les ingrédients destinés à enrichir les produits carnés en protéines végétales ou à élaborer des produits végétariens.

Le filage est la technologie la plus sophistiquée et la plus coûteuse. Elle consiste à augmenter le $\mathrm{pH}$ de la solution protéique jusqu'à une valeur comprise entre 10 et 12 . Après filtration pour éliminer les particules insolubles, puis extrusion à froid au travers d'une filière, des filaments fins $(<100 \mu \mathrm{m})$ comportant des chaînes polypeptidiques sont immédiatement coagulés dans un bain de $\mathrm{pH}$ compris entre 2 et 5 et contenant des sels. Les fibres insolubles ainsi formées sont assemblées, éventuellement étirées pour parfaire la structuration fibreuse, puis lavées et neutralisées au $\mathrm{pH}$ habituel de la viande $(5,5)$. La dernière étape consiste à assembler différents paquets de fibres avec un liant protéique tel que l'ovalbumine, la caséine ou encore des protéines de soja, puis à fixer l'ensemble par chauffage. Des analogues de viande ont ainsi été produits dans les années 1990 et jugés acceptables par des panels de dégustateurs, mais ces développements sont restés au stade de la recherche, essentiellement pour une question de coût de production.

Il est intéressant d'évoquer le « quorn», nom commercial du seul véritable analogue de viande sur le marché. Il est vendu actuellement dans les pays occidentaux (USA et Europe du Nord) sous la forme de cubes ou de tranches et/ou incorporé dans des plats préparés. Il s'agit de mycoprotéines produites par la culture du champignon filamenteux Fusarium venenatum; les hyphes pouvant mesurer quelques centimètres sont agglomérés par un liant tel que le blanc d'œuf ce qui permet d'obtenir, après chauffage, un aliment protéique solide à texture fibreuse pouvant être cuisiné comme de la viande. L'histoire du développement de ce produit est instructive. Alors que la technique de production est très simple, peu coûteuse par rapport à celle de la viande in vitro et qu'elle suscite peu d'interrogations au plan sanitaire, il a fallu plus de 20 ans depuis le dépôt du brevet et les premiers développements industriels pour que le «quorn » prenne une part de marché significative, bien qu'encore marginale en comparaison des viandes. Ceci s'explique par le temps nécessaire pour qu'un nouvel analogue de viande soit accepté par les consommateurs et pour que les autorités publiques délivrent des autorisations de mise sur le marché en se fondant sur des preuves expérimentales tangibles de qualité sanitaire.

\section{2 / Qu'est-ce que la viande artificielle?}

\section{1 / La viande : un muscle trans- formé}

La viande (cf. encadré 1) correspond au tissu musculaire qui a subi des transformations structurales et biochimiques au cours des phases de rigidité cadavérique et de maturation. Le tissu musculaire squelettique est considéré comme le tissu «noble» des animaux. C'est un tissu composite (figure 1A) essentiellement constitué de fibres musculaires rassemblées en faisceaux et occupant $80 \%$ de la surface du muscle. Chaque fibre ou chaque faisceau de fibres est enveloppé par du tissu conjonctif. Les réserves en lipides sont principalement contenues dans des adipocytes localisés entre les 


\section{Encadré 1. Qu'est-ce que la viande?}

Selon le codex alimentarius (2005), la viande correspond à toutes les parties d'un animal destinées à la consommation humaine ou jugées saines et propres à cette fin. Traditionnellement, en Europe, est considérée comme de la viande celle d'origine musculaire issue :

- des animaux de boucherie : bovin, veau, porc, mouton, agneau, cheval, chevreau ;

- des animaux de basse-cour : poulet, dinde, canard, pintade, oie, pigeon, lapin ;

- du gibier : sanglier, chevreuil, lièvre...

II existe aussi des viandes plus "exotiques " issues de muscles d'animaux comme le chameau, l'autruche, le crocodile et le kangourou. Chaque région du monde possède ses spécificités en la matière (Denoyelle 2008). Cette diversité est accentuée par les différents types d'animaux (race, âge, sexe) et la variabilité des morceaux de viande d'une carcasse présentés et cuisinés de diverses manières en fonction de leurs caractéristiques.

faisceaux de fibres. Des vaisseaux sanguins irriguent l'ensemble afin d'apporter l'oxygène et les nutriments nécessaires au fonctionnement du muscle, et des nerfs moteurs véhiculent l'influx nerveux. La composition chimique du muscle est caractérisée par une forte teneur en eau (75\%) et en protéines (environ $20 \%$ du tissu frais), et par une faible teneur en lipides (généralement de 2 à $8 \%$ selon les types de muscles) contenant différentes classes d'acides gras, majoritairement saturés (43 à 52\%) et monoinsaturés (42 à 45\%) (Bauchart et Gandemer 2010).

Les qualités sensorielles de la viande (tendreté, jutosité, goût) dépendent des composantes du muscle (tissu conjonctif en particulier pour la viande bovine, fibres musculaires et adipocytes) et de la cinétique d'évolution post-mortem du muscle. Le tissu conjonctif, riche en col- lagène, qui évolue peu pendant la maturation, est responsable de la dureté de base de la viande. Au cours de la maturation, des modifications des propriétés biochimiques et structurales induisent une augmentation de la tendreté. La vitesse de ce phénomène dépend des propriétés des fibres musculaires. Pour les viandes blanches (volailles), la maturation est très rapide (quelques jours) par opposition aux viandes rouges (de l'ordre de 14 jours).

\section{2 / Les étapes de la formation du muscle}

Les fibres musculaires se mettent en place pendant le développement embryonnaire et fotal (figure 1B) selon des principes biologiques comparables entre les espèces animales. Toutefois, la cinétique de mise en place diffère selon la maturité de chaque espèce à la naissance (Picard et al 2002). Au début du développement, des cellules souches se différencient en cellules précurseurs du muscle squelettique (pré-myoblastes). Puis, les myoblastes se divisent et fusionnent pour former des cellules plurinucléées (myotubes). Dans les myotubes, l'appareil contractile s'organise et le métabolisme se met en place pour donner naissance aux fibres musculaires. Le centre des fibres est occupé par les protéines contractiles et les noyaux sont localisés en périphérie. La croissance musculaire se réalise par hyperplasie (augmentation du nombre de fibres), puis par hypertrophie (augmentation de leur taille), et le nombre total des fibres est fixé pendant la vie fotale ou après la naissance selon les espèces (Picard et al 2002). Le processus d'hypertrophie se produit grâce à la fusion des cellules satellites (figure 1) avec les fibres existantes.

\section{3 / Les cellules musculaires peuvent être cultivées in vitro}

Toutes les étapes de formation du muscle peuvent être reproduites in vitro (figure 2). La culture primaire de myoblastes est utilisée depuis de nombreuses années à des fins de recherche. Le principe consiste à extraire les cellules par digestion enzymatique de la trame conjonctive à partir de muscle prélevé sur un animal (fœtus ou adulte). Ces cellules sont ensemencées dans un milieu adapté à leur survie, leur prolifération et leur différenciation. Pour les muscles d'adulte, des petits morceaux de muscles (explants)

Figure 1. Structure et formation du tissu musculaire.

A)

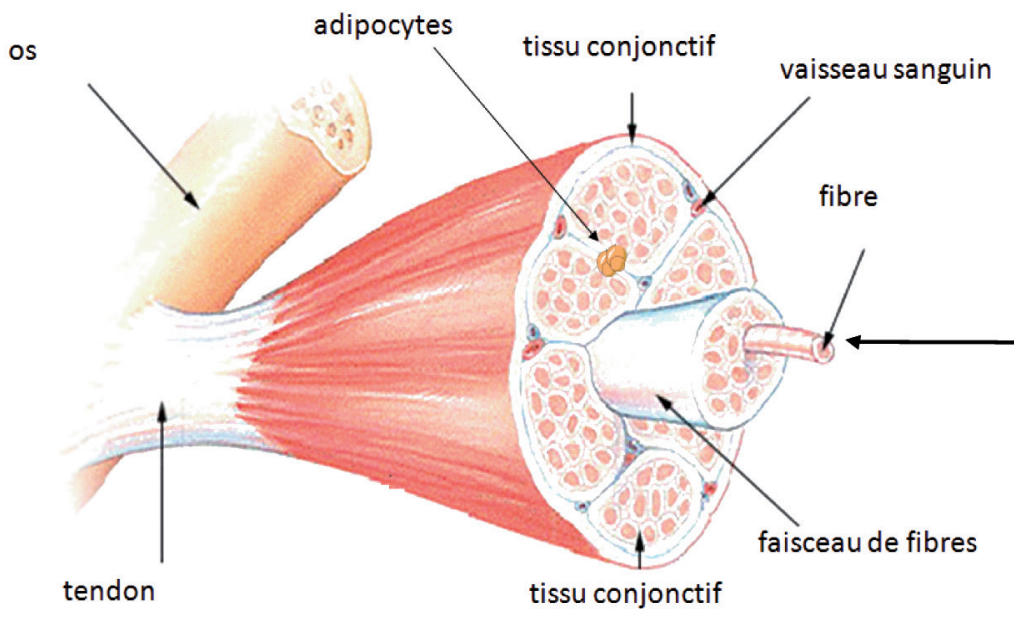

http://training.seer.cancer.gov/anatomy/muscular/structure.html

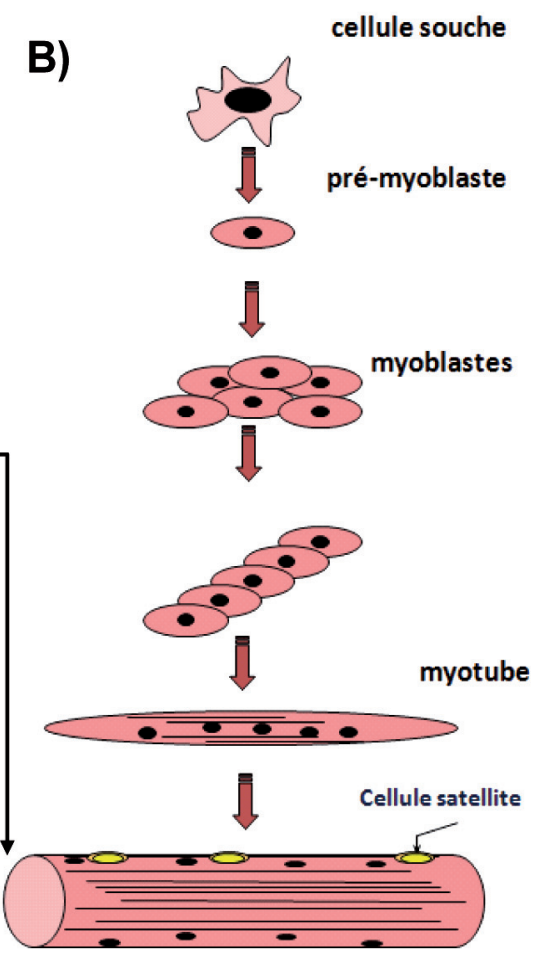

fibre musculaire 
Figure 2. Culture de cellules de tissu musculaire de bovins (photos A. Delavaud).
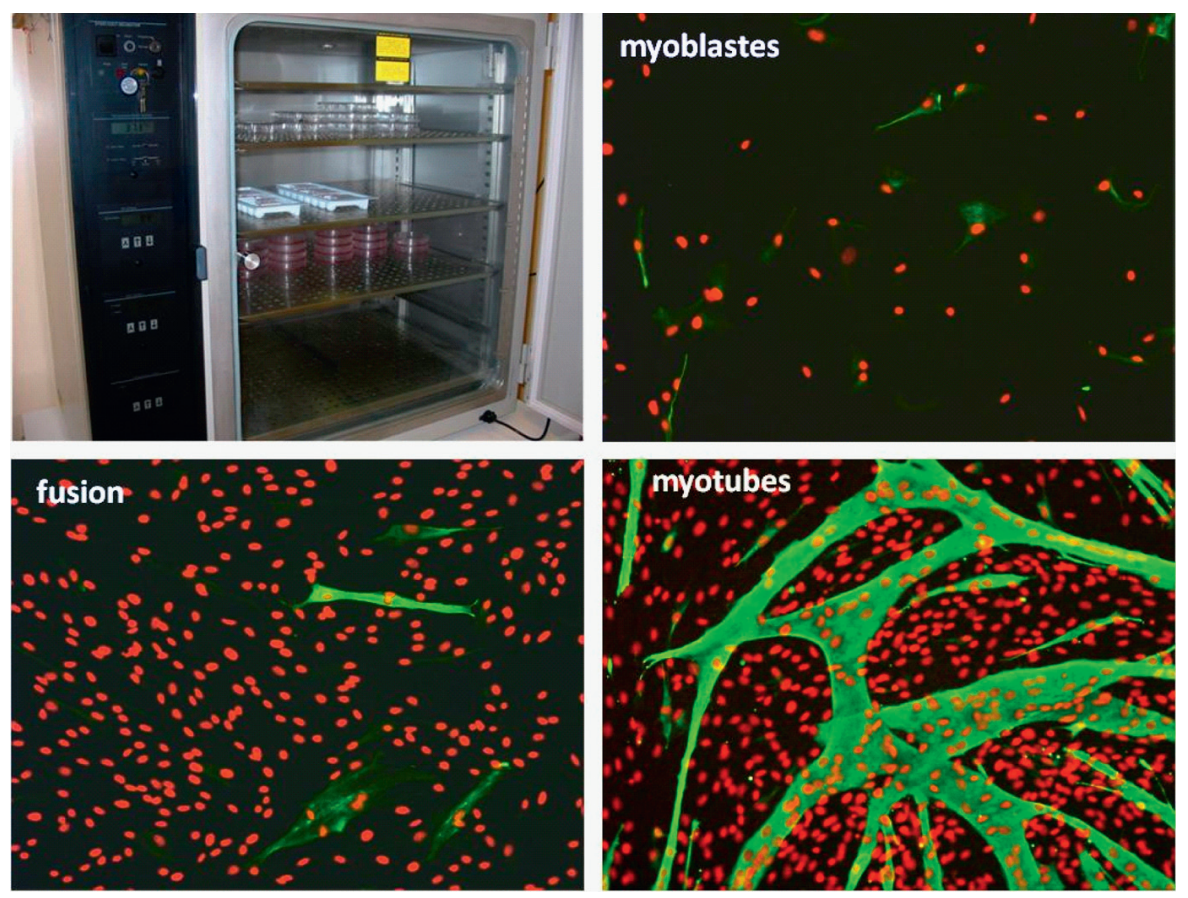

sont déposés dans une boîte de Petri contenant du milieu de culture. Les cellules sortent progressivement du tissu et envahissent le fond de la boîte. Elles peuvent alors être repiquées et ensemencées (Cassar-Malek et al 1999). Quelle que soit la méthode d'isolement, les cellules musculaires prolifèrent, puis s'alignent et fusionnent pour former des myotubes (figure 2). Les boîtes de culture sont placées dans un incubateur à $37^{\circ} \mathrm{C}$, sous atmosphère enrichie en $\mathrm{CO}_{2}$. Pour une croissance optimale, le milieu de culture doit être riche en nutriments et en facteurs de croissance, généralement apportés par du sérum de veau fotal ou de cheval. Les milieux peuvent être facilement envahis par des contaminants tels que bactéries et champignons. Aussi, ils sont enrichis en antibiotiques et en fongicides. Au final, une monocouche de myotubes tapisse les boîtes. On est alors loin d'observer un morceau de muscle avec ses différentes composantes (fibres, tissus conjonctif et adipeux) et encore moins de la viande avec toute sa diversité (morceaux, sang...) et ses propriétés sensorielles et nutritionnelles.

\section{4 / Production de viande in vitro}

La culture in vitro de cellules musculaires est préconisée par certains chercheurs (Datar et Betti 2010, Post 2012) et par le «In vitro meat consortium » pour la production de viande. Les recherches visent à développer des techniques d'ingénierie tissulaire pour produire des structures tridimensionnelles (3D). Une start-up américaine, "Modern Meadow » (Prairies Modernes) développe une « imprimante 3D capable d'imprimer de la viande » (voir encadré 2). pour la transplantation. souches embryonnaires et adultes (cellules satellites) sont des sources prometteuses de cellules. Jusqu'à présent, les seules lignées de cellules souches cultivées avec succès l'ont été chez des espèces modèles et chez l'Homme. L'établissement de telles lignées à partir d'animaux d'élevage n'a jamais été rapporté. Chez ces animaux, des cellules souches adultes (cellules satellites) ont déjà été isolées à partir de muscle squelettique de mouton (Dodson et al 1986), de bovin (Dodson et al 1987), de poulet (YablonkaReuveni et al 1987), de dinde (McFarland et al 1988) et de porc (Wilschut et al 2008). Cependant, leur capacité proliférative in vitro est limitée et ne permet pas d'obtenir des lignées. Elle doit encore être améliorée pour la production de viande. Les cellules musculaires nécessitent des supports solides pour être cultivées et se différencier, ce qui implique d'utiliser de grandes surfaces de culture et donc de nombreux incubateurs. Une alternative est la culture sur des matrices biologiques ou synthétiques dans des bioréacteurs. Les cellules souches peuvent, par exemple, être cultivées à la surface de microbilles en suspension et proliférer presque indéfiniment ( $>100$ doublements). Pour une application à la production de viande de culture, cette matrice devrait être comestible ou biodégradable.

Le deuxième défi concerne la formulation des milieux de culture. De nombreux nutriments (glucides, acides aminés, lipides, vitamines...), facteurs de croissance (TGF $\beta$, FGF, IGF) et hormones (insuline, hormones thyroïdiennes et/ou hormone de croissance) sont nécessaires pour maintenir la viabilité des cellules et leur permettre de proliférer. Les cellules souches sont cultivées dans un milieu contenant des nutriments et du sérum de veau fotal ou de veau nouveau-né. La nature exacte des facteurs présents dans le sérum qui assurent la croissance et la différenciation des cellules est encore inconnue, mais il est établi que certains lots de sérum sont mieux adaptés que d'autres à la culture cellulaire. Pour la production de viande in vitro destinée à la consommation humaine, un verrou à lever est de produire à l'échelle industrielle des milieux stériles, sans produit d'origine animale

\section{Encadré 2. Une imprimante $3 D$ capable d'imprimer de la viande.}

L' " imprimante » comporte deux cartouches (similaires aux cartouches d'imprimante à jet d'encre) et deux têtes d'impression : l'une pour le type de cellules du tissu à concevoir (foie, poumon, vaisseau sanguin) et l'autre pour une matrice soluble (hydrogel) qui va servir de support aux cellules (École de Technologie Supérieure de Montréal 2012). Pour la production de muscle humain, la cartouche contient des cellules souches. Une fois imprimées, ces cellules fusionnent pour former un tissu musculaire vivant. Cette technique a été initialement développée à des fins médicales par la société "Organovo" pour reconstruire (ou créer) des tissus et des organes (organes artificiels irrigués) 
comme le sérum et idéalement de composition définie. Des milieux synthétiques sans sérum (Van Eelen et al 1999) ou préparés à partir d'extraits de bactéries ou de cellules de levures (Halász et Lásztity 1991), de champignons (Benjaminson et al 2002) ou de micro-algues (Tuomisto et Teixeira de Mattos 2011) ont été proposés.

Enfin, le troisième défi est de produire, en grande quantité, un tissu le plus semblable possible au tissu musculaire des animaux d'élevage (structure, propriétés nutritionnelles...), ce qui n'a encore jamais été rapporté dans la littérature. $\mathrm{Au}$ mieux, ce seront des suspensions de myotubes, ou des petites fibres musculaires qui seront obtenues, constituant un tissu d'une épaisseur de moins d'un millimètre.

Ainsi, la production industrielle de viande de culture semble envisageable, si un certain nombre de difficultés sont levées, les deux plus importantes étant :

- le coût très élevé des procédés actuels (250 000 euros pour la fabrication du premier hamburger artificiel) dû à l'utilisation d'enceintes stériles pour éviter les contaminations microbiennes, à l'utilisation d'incubateurs et de bioréacteurs, et de milieux de culture onéreux ;

- le manque de ressemblance du produit obtenu (de type viande laminée) à de la viande issue d'animaux en matière d'aspect, de texture, de goût, etc. Les étapes les plus critiques seront d'obtenir des tissus musculaires en trois dimensions à partir de lignées de cellules souches établies, dans des milieux de culture sans additifs d'origine animale, à un prix suffisamment bas, puis d'industrialiser ce processus, nécessitant probablement plusieurs dizaines d'années de mise au point. La viande de culture pourrait être combinée avec d'autres innovations durables, comme la culture de micro-algues, pour produire les milieux de culture (Tuomisto et Teixeira de Mattos 2011).

\section{3 / Intérêts et limites de la viande artificielle pour la nutrition humaine}

Avant d'aborder les propriétés nutritionnelles de la viande artificielle, il est important de rappeler que la viande apporte aujourd'hui dans notre alimentation des protéines particulièrement riches en acides aminés indispensables (non synthétisables par notre organisme), en quantité équilibrée par rapport à nos besoins nutritionnels (Rémond et al 2010). De plus, la viande est riche en oligoéléments comme le sélénium, le zinc, mais surtout en fer (Bauchart et Gandemer 2010), en particulier en fer héminique dont le taux d'absorption intestinale est supérieur à celui du fer d'origine végétale. La viande est également une source majeure de vitamines hydrosolubles du groupe B, notamment de vitamine B12 d'origine strictement animale. Elle participe modestement aux apports totaux en lipides de notre alimentation, soit environ 8\% en France (Hébel 2007), mais contribue significativement aux apports en acides gras polyinsaturés à longue chaîne des séries n-6 et n-3 (Bauchart et Thomas 2010), indispensables à l'organisme.

Aucun des nutriments généralement pris en compte pour établir un régime équilibré n'est spécifique de la viande. Il est donc possible de la remplacer par d'autres sources alimentaires si celles-ci contiennent des protéines en quantité suffisante. C'est ce que font les végétariens. Pour pallier les déséquilibres en acides aminés indispensables de certaines protéines végétales, il est en effet possible de les combiner entre elles pour rétablir un équilibre compatible avec les besoins de notre organisme. Toutefois, avec ce type de régime alimentaire, des difficultés peuvent apparaître pour couvrir les besoins en vitamine B12, fer et zinc, surtout chez les personnes ayant des besoins élevés (enfant en croissance, femme enceinte ou allaitante, personne âgée, sportif).

Outre ses qualités nutritionnelles, la viande joue également un rôle structurant dans la composition de nos repas, sa consommation étant généralement associée à celle de féculents ou de légumes. S'il devient possible de produire une viande artificielle contenant tous les composés nutritionnels naturellement présents (protéines, fer, vitamines...) et acceptable sur le plan organoleptique, son intérêt sera de fait équivalent à celui de la viande, ceci à condition qu'elle n'apporte pas de composés indésirables (antibiotiques, hormones exogènes, facteurs de croissance...). De plus, s'agissant d'un aliment artificiel, il est théoriquement imaginable d'enrichir ce produit en certaines molécules d'intérêt, voire d'assurer un équilibre optimal en acides gras (moins d'acides gras saturés et plus d'acides gras polyinsaturés).

Est-ce que la production de viande artificielle permettra d'atteindre ces objectifs ? Et surtout, quel sera l'intérêt d'une étape de synthèse de cellules musculaires in vitro, par rapport à un assemblage direct des nutriments constitutifs ?

Il semble actuellement impossible de répondre à la première question. En ce qui concerne l'intérêt d'une production de viande in vitro, celui-ci n'est pas évi- dent. En effet, la seule différence entre la consommation d'une viande artificielle et l'ingestion directe des nutriments nécessaires à sa fabrication, serait de fournir les acides aminés sous la forme de protéines, principalement sous la forme d'actine et de myosine (les protéines majoritaires du muscle), ce qui ne présente pas une valeur santé particulière. Les cellules musculaires n'étant pas capables de synthétiser elles-mêmes les acides aminés indispensables, la synthèse de la viande artificielle nécessitera d'apporter dans le milieu de culture ces acides aminés sous forme libre. S'ils ne sont pas produits par l'industrie chimique, ces acides aminés devront provenir d'autres sources de protéines d'origine animale, végétale, fongique ou microbienne. Ceci nécessitera, dans tous les cas, des étapes d'extraction et d'hydrolyse de ces protéines qu'il faudrait industrialiser. Ces étapes se déroulent naturellement dans le tube digestif des animaux. De plus, les ruminants transforment des sources protéiques à faible teneur en acides aminés indispensables en protéines de bonne qualité (c'est-à-dire à forte teneur en acides aminés indispensables), via la synthèse de protéines microbiennes réalisée dans le rumen. En effet, environ $2 / 3$ des acides aminés utilisés par les ruminants pour leur métabolisme sont d'origine microbienne.

En raison de l'augmentation conjointe de la population mondiale et du niveau de vie dans les pays émergents, la demande en protéines de bonne qualité va considérablement augmenter dans le futur. Le procédé qui conduit à la viande artificielle permettra-t-il de répondre à cette attente ? Cela semble peu probable puisqu'il ne participera pas directement à l'accroissement de la disponibilité en protéines, mais doit plutôt être considéré comme une étape de transformation pour produire des protéines de qualité comparables à celles de la viande issue d'animaux. L'assurance d'un apport protéique de qualité et suffisant pour la population passe plutôt par un changement de comportement alimentaire dans les pays développés où la consommation moyenne en protéines animales pourrait être sensiblement réduite sans conséquences néfastes pour la santé. Par exemple, la consommation moyenne de protéines des adultes en France est 1,5 fois plus élevée que les recommandations, et la part des protéines animales dans cette consommation est de $70 \%$, alors que les recommandations sont d'atteindre un équilibre entre les apports de protéines animales et végétales. De plus, les études prospectives montrent qu'il pourrait être possible de nourrir la planète sans mettre en péril notre environnement, simplement en réduisant les gaspillages observés tout au long de la chaîne alimentaire jusqu'à leur distribution et leur consommation 
(Esnouf et al 2011). Ces gaspillages représentent environ un tiers de la production agricole.

En conclusion, d'un point de vue nutritionnel, la viande artificielle ne semble pas présenter d'intérêt particulier par rapport à un autre aliment artificiel, plus simple, qui serait formulé directement à partir des nutriments nécessaires à son élaboration. Si sa seule justification repose sur la production d'une source de protéines n'entraînant pas la mort d'un animal, l'utilisation directe dans notre alimentation des ressources végétales disponibles pourrait permettre d'atteindre un équilibre alimentaire satisfaisant sans avoir recours à l'étape supplémentaire d'une synthèse artificielle.

\section{4 / Intérêts et limites de la viande artificielle pour résoudre les questions po- sées par l'élevage moderne}

Selon ses promoteurs, la viande artificielle permettrait de diminuer les inconvénients, réels ou supposés, de l'élevage moderne. Nous examinons ici la nature de ces inconvénients en précisant dans quelle mesure un premier bilan comparatif entre la production de viande artificielle et l'élevage peut être dressé.

\section{1 / Le droit de tuer les animaux pour les manger et le mal-être animal dans l'élevage}

Le droit qu'aurait l'Homme de tuer des animaux renvoie à des considérations d'ordre éthique, donc philosophique. La forme la plus aboutie de ce refus est située dans les démarches végétarienne et végétalienne. Le végétarien « éthique » ne nie pas que la vie animale naturelle implique la prédation, mais conteste ce droit à l'Homme. Le fondement philosophique de cette démarche est « l'antispécisme », qui postule que toutes les espèces animales disposent d'un droit à la vie, et que l'Homme n'est pas autorisé à exploiter et à tuer d'autres espèces sous prétexte qu'il en a les moyens intellectuels et techniques. Le philosophe Lestel (2011) considère que l'anti-spécisme contient une contradiction majeure : il revendique l'égalité de toutes les espèces animales, dont l'Homme, mais refuse d'accorder le droit à la prédation à une seule espèce, l'Homme, alors qu'il reconnaît ce droit à toutes les autres. Ces débats font qu'il n'existe pas d'assise juridique à une interdiction d'abattage des animaux domestiques. Le végétarien éthique pourrait donc accepter de manger la viande artificielle.

Toute autre est la question de la « souffrance » animale. Il y a 10000 ans,
l'Homme a inventé la domestication d'animaux dont la vie est désormais sous contraintes. La condamnation morale de la « souffrance » inutile des animaux est présente dans la philosophie antique, avec Pythagore, un végétarien éthique (VI ${ }^{\text {ème }}$ siècle av. JC), ou encore dans l'ancien testament. La question d'aujourd'hui porte sur l'abus de pouvoir de l'Homme sur ses animaux domestiques suite à la modernisation des techniques d'élevage. Les critiques les plus emblématiques portent sur la grande taille des élevages et leurs conséquences sur la vie des animaux maintenus en grand nombre dans des bâtiments fermés. Elles portent aussi sur la contention des animaux et les " mutilations » pratiquées pour améliorer les performances d'élevage (écornage des veaux, castration des porcelets...). Dans les pays développés, une règlementation de plus en plus précise encadre l'élevage. Elle évolue constamment pour modifier les pratiques en vue d'améliorer le bien-être des animaux. En Europe par exemple les anabolisants sont interdits dans la finition des bovins. Cette évolution résulte d'un compromis entre la contrainte économique et la demande sociale, mais se heurte à des limites. Par exemple, la vache souffre lorsqu'on lui enlève son veau juste après le vêlage, mais sans ce sevrage précoce, il n'y a pas de production laitière bon marché, et pour l'heure, avec 7 milliards d'habitants, la démocratisation du lait est à ce prix. Malgré ces limites, il reste encore de nombreuses marges de progrès. Toutefois, tant qu'il y aura des élevages, il sera difficile d'offrir aux animaux domestiqués des conditions de vie idéales proches de celles qu'ils auraient eues à l'état naturel. Et la viande artificielle dispose là d'un avantage radical.

\section{2 / Les impacts négatifs de l'éle- vage sur l'environnement}

Une étude récente sur les impacts environnementaux de la viande artificielle par analyse de cycle de vie (Tuomisto et Teixeira de Mattos 2011, complétée par Tuomisto et Roy 2012) conclut à l'intérêt environnemental de la viande artificielle par rapport aux viandes de ruminants et de monogastriques sur trois points : les émissions de gaz à effet de serre, la consommation d'eau et la consommation d'énergie. Cette étude appelle deux remarques : $i$ ) les calculs ont été réalisés alors qu'on ne connait pas précisément les procédés industriels de production qui seront retenus et ii) l'utilisation de facteurs de croissance et d'hormones pour produire la viande artificielle n'est pas évoquée par les auteurs et génèrera certainement des résidus dont les impacts n'ont pas été pris en compte. On peut d'ailleurs s'interroger sur la politique future des autorités sanitaires : l'utilisation d'hormones pour sti- muler la production de viande étant interdite, sera-t-elle autorisée pour la viande artificielle?

En 2006, la FAO a attribué aux filières d'élevage (lait et viande) une part de $18 \%$ des émissions anthropiques mondiales de Gaz à Effet de Serre (GES) contribuant au réchauffement climatique. Ce chiffre largement médiatisé inclut les fermentations des systèmes digestifs et des déjections des animaux, la production des aliments consommés et celle des intrants tels que les fertilisants, les activités des industries liées à la production d'aliments, l'impact de la déforestation dans le cas du soja, les transports, la consommation d'énergie et de carburant dans la ferme. Mais différentes études françaises (Dollé et al 2011) ou européennes (Leip et al 2010) précisent que l'impact de l'élevage herbivore sur les GES est plus faible en raison notamment du rôle important des prairies naturelles utilisées par les herbivores dans le stockage du carbone dans le sol, dont il n'était pas tenu compte jusqu'à présent. Par ailleurs, de nombreuses recherches visent à réduire la production de GES, notamment celle du méthane par les herbivores qui produisent $80 \%$ des GES de l'élevage mondial mais seulement un tiers de la production de viande. Toutefois, $70 \%$ des GES de l'élevage seraient émis par les pays émergents et en développement (GIEC 2007), pour lesquels la réduction des émissions n'est guère prioritaire. Enfin, il faut prendre en compte le fait qu'une grande partie de la production de viande de ruminants est indissociable de la production laitière $(40 \%$ de la production française vient du troupeau laitier). La réduction des GES liés à la production de viande est donc possible bien que difficile à concrétiser.

Selon Tuomisto et Teixeira de Mattos (2011), l'émission de GES par la production de viande artificielle serait respectivement environ 20,12 et 8 fois plus faible que celle émise par la production des viandes de bœuf, de porc et de volailles. Malgré les très fortes incertitudes mentionnées ci-dessus, la production de viande artificielle émettrait vraisemblablement moins de GES que celle de viande de ruminants et probablement de porcs et volailles. Mais la disparition concomitante de la viande produite au pâturage réduirait le stockage de carbone dans les sols. Quant aux activités industrielles ou agricoles pour l'élevage, elles ne disparaîtraient pas totalement mais seraient l'objet de reconversions au moins partielles. Etant donnée la part importante et croissante des pays émergents dans les émissions de GES de l'élevage mondial, et du fait qu'une grande partie de la viande de ruminants est produite à partir de l'élevage laitier, la réduction 
des émissions de GES suite à la production de viande artificielle est difficile à évaluer.

Les excréments contenant des nitrates constituent des fertilisants actuellement épandus sur les terres labourables qu'il conviendrait de remplacer par d'autres d'engrais en absence d'élevage. La croissance et la concentration de l'élevage dans certaines zones a conduit à dépasser la limite règlementaire de nitrates dans ces eaux, limite qui a été fixée par précaution à $50 \mathrm{mg}$ /litre d'eau potable (directive nitrate européenne, 1991). La viande artificielle ne produirait évidemment aucun effluent d'élevage, mais sa production industrielle entraînerait d'autres pollutions dont l'inventaire est prématuré. En première approche, son bilan nitrate serait meilleur que celui de l'élevage, surtout par le fait que le contrôle de ces pollutions est plus maîtrisable en usine que l'épandage dispersé sur des régions entières.

Alors qu'une pénurie d'eau dans certaines régions du monde est à craindre au cours du XXI ${ }^{\text {ème }}$ siècle, le chiffre de 15000 litres d'eau pour produire un $\mathrm{kg}$ de viande de bœuf (Mekonnen et Hoekstra 2012) a été largement médiatisé. Il s'agit d'un calcul sur le cycle complet de l'eau dans un écosystème : plus de $95 \%$ de cette empreinte eau de l'élevage est constituée par une eau virtuelle, essentiellement l'évapotranspiration sur les surfaces dédiées à l'élevage, fortement liée à la pluviométrie. L'eau réellement consommée par les animaux, les bâtiments d'élevage ou par l'irrigation des cultures dédiées aux animaux s'élève entre 200 et 550 litres par $\mathrm{kg}$ de viande de bœuf (Corson et Doreau 2013). Celle des porcs et des volailles est encore plus faible. L'impact de l'élevage sur la ressource en eau est encore plus faible lorsqu'on raisonne en termes de stress hydrique, celuici n'existant que dans certaines zones géographiques (Ridoutt et al 2012). Au final, malgré l'absence de données précises, la production de viande artificielle devrait consommer aussi peu d'eau que la viande naturelle.

Tuomisto et Teixeira de Mattos (2011) ont estimé que la consommation d'énergie fossile pour la viande artificielle serait légèrement inférieure à celle de l'élevage de porc et de volailles, et deux fois plus faible que celle de viande de ruminant. Dans ce cas également, l'absence de connaissances sur le fonctionnement des usines de production de viande artificielle et sur les intrants nécessaires laisse subsister un fort doute sur la précision des calculs réalisés par ces auteurs et les hypothèses qu'ils ont prises. De ce fait, leurs conclusions ne peuvent pas être confirmées par la communauté scientifique.
En définitive, la viande artificielle présenterait un intérêt modéré pour réduire les GES et les pollutions par les nitrates, un intérêt limité pour réduire la consommation d'énergie fossile, et probablement une absence d'intérêt pour la disponibilité de la ressource en eau. En revanche, une grande incertitude subsiste sur la création d'autres problèmes environnementaux par la fabrication de viande artificielle; par exemple, le rejet dans la nature de molécules organiques issues des milieux de culture. Un bilan environnemental complet est prématuré en l'absence d'une définition précise des modes de production industrielle de la viande artificielle.

\section{3 / La faim dans le monde et les besoins en terres}

L'interrogation sur la capacité de la planète à nourrir sa population n'est pas nouvelle. Déjà Malthus, il y a 200 ans, puis le club de Rome en 1970, posaient ce type de question. Malgré la relative abondance de ressources alimentaires, la FAO indique qu'environ un milliard d'humains ne mangent pas tous les jours à leur faim. D'où l'idée d'utiliser des terres labourables mobilisées par l'élevage intensif pour la production de végétaux pour l'alimentation humaine.

L'élevage mobilise en effet $70 \%$ des terres agricoles, arables ou non. Dans le cas des terres arables, il existe une concurrence avec l'alimentation humaine, qui est plus forte pour les élevages de porcs et de volailles, dont les aliments sont cultivés en totalité. La production de viande artificielle présenterait donc l'intérêt de libérer des terres labourables. Quant aux pâturages naturels pour les ruminants, il s'agit en grande partie (surtout en zone tropicale) de zones peu ou pas cultivables (montagnes, sols pauvres) qui sont en concurrence réduite avec l'Homme, l'élevage y constituant souvent la seule activité humaine possible. Ces espaces pâturés fournissent des externalités positives telles que l'entretien des paysages, et les maintiens de la biodiversité et d'une activité économique. De plus, l'élevage présente incontestablement une dimension sociale particulièrement marquée dans les pays du Sud (Alary et al 2011).

Les déterminants de la malnutrition d'une partie de la population humaine sont en réalité multiples : guerres, mauvaise gouvernance politique, non solvabilité des populations malgré une offre suffisante. L'économiste Amartya Sen, prix Nobel d'économie en 1998 pour ses travaux sur les famines, conclut que les malnutritions contemporaines sont dues majoritairement à des problèmes d'ordre politique induisant des inégalités dans l'accès à la nourriture (Sen 1981). Selon ses analyses, l'élevage consommateur de céréales n'expliquerait pas la « faim dans le monde ». Certains experts constatent en effet que, malgré quelques rares épisodes de pénurie, l'offre de l'élevage mondial a réussi à suivre depuis 50 ans l'accroissement de la demande mondiale grâce aux gains de productivité et secondairement, grâce à des suppléments de surfaces cultivées. Cette demande a suivi la démographie mondiale, des 3 milliards d'humains de 1960 jusqu'aux 7 milliards de 2011. Quant aux 2 milliards d'humains supplémentaires qu'il faudra nourrir à l'horizon 2050, la FAO (2009) estime qu'il sera possible techniquement de l'assumer grâce à une agriculture et un élevage plus efficients.

\section{5 / L'acceptation dans le futur}

Plusieurs exemples récents (biotechnologies et nanotechnologies) montrent que les consommateurs européens n'adoptent pas les nouvelles technologies agroalimentaires avec autant d'enthousiasme qu'espéré initialement (Verbeke 2011). Au-delà des conditions de son acceptabilité par les consommateurs et les citoyens, les objectifs des acteurs du marché potentiel de la viande artificielle méritent d'être analysés. Les motivations des équipes de recherche et de leurs financeurs ne sont pas toujours convergentes : certains considèrent qu'il s'agit d'une alternative à la viande " naturelle » s'adressant à tous les consommateurs sensibilisés aux questions sociétales et pas seulement à ceux qui ont renoncé à la consommation de viande. D'autres la voient comme un substitut aux produits à base de protéines végétales qualifiés d'ersatz peu appétents. Les derniers, enfin, considèrent que la viande artificielle peut permettre de reconquérir les végétariens avec plus de diversité dans les aliments disponibles. Derrière ces visions se dessine la place que pourrait prendre la viande artificielle (marchés de masse ou niches pour des clientèles très ciblées). Son positionnement comme une alternative, un substitut ou un complément à la viande conventionnelle jouera un rôle crucial pour l'acceptation dans le futur, car les consommateurs se réfèreront aux produits avec un positionnement similaire sur le marché.

\section{1 / Principes de l'acceptabilité par les citoyens-consommateurs}

Plusieurs études ont identifié des points modulant l'acceptation des nouvelles technologies alimentaires par les citoyensconsommateurs (Hopkins et Dacey 2008, Frewer et al 2011, Rollin et al 2011). Une première série de déterminants a trait à la perception des avantages et des 
risques de la technologie pour le citoyen, la société dans son ensemble et les promoteurs de la technologie. Une deuxième série de déterminants est liée à la technologie elle-même : la croyance générale dans la science, le caractère artificiel du produit, la perception du caractère contrôlable (ou non) du processus technologique et la confiance dans le cadre réglementaire. Ces facteurs influent sur l'acceptabilité d'une nouvelle technologie. Des associations cognitives peuvent induire des activations d'attitudes par des associations positives ou négatives avec, par exemple, d'autres technologies. Ainsi, l'expression "in vitro » rappelle la fécondation in vitro ou la production d'hormones de laboratoire. Enfin, les différences socio-culturelles et le niveau de sensibilisation et de participation du public dans le développement technologique sont des facteurs qui façonnent la réaction des consommateurs.

Parmi toutes les objections potentielles, trois ont été récemment reprises et discutées pour la viande artificielle :

- Le caractère non naturel du processus de fabrication qui pourrait à lui seul conduire à de fortes réticences des citoyensconsommateurs considérant qu'il s'agit d'une nouvelle manipulation de la nature au profit de l'Homme. Cependant, le caractère artificiel peut être vu comme un avantage s'il réduit les inconvénients de la production de viande naturelle (Hopkins et Dacey 2008). Par ailleurs, la culture cellulaire in vitro utilise des mécanismes biologiques naturels, et ces technologies sont très largement acceptées dans d'autres domaines, fécondation in vitro et médecine réparatrice par exemple (Welin et van der Weele 2012).

- Le dégoût («yuck factor ») que les consommateurs éprouveraient à l'idée de consommer de la viande artificielle. A l'instar de nombreuses nouvelles technologies, le seul fait de commercialiser un produit innovant génère des craintes. Pour la viande artificielle, cette néophobie potentielle pourrait être aggravée par le fait que l'aliment n'est pas un produit comme un autre : la dimension culturelle, voire identitaire, de l'alimentation plus le fait que l'aliment devienne «soi» par le biais des transformations biologiques après l'ingestion accentue cette crainte et donc la réticence potentielle. A titre d'exemple, la mise sur le marché de produits tels que le surimi ou le tofu a suscité des débats : bien que ces produits recourent à une matière première connue du grand public, leur caractère novateur dans les sociétés occidentales a suscité des inquiétudes avant de s'imposer sur le marché. Les promoteurs de la viande artificielle arguent qu'une fois présenté le processus de fabrication, le dégoût des consommateurs décroîtra, et que cette réticence n'a rien de spécifique à la vian- de artificielle (Hopkins et Dacey 2008, Bath et Bath 2011).

- Le danger que pourrait représenter la diffusion d'un produit issu d'une technologie innovante, mais non validée et aux effets non évalués sur la santé humaine. Comme pour les organismes génétiquement modifiés, la mise sur le marché de viandes artificielles soulèverait des controverses. Leur adoption massive passerait par une révélation progressive de leurs avantages/inconvénients assortie de garanties apportées par la puissance publique et les acteurs (Driessen et Korthals 2012).

Les réactions individuelles seraient liées à la technologie de production et au produit proposé. La première réaction serait essentiellement celle du citoyen par rapport à la manière dont la viande in vitro sera produite. La deuxième réaction serait principalement celle du consommateur face au produit résultant, et à sa capacité à satisfaire un besoin existant. Les critères d'acceptabilité de la viande artificielle sont donc de deux ordres. L'un est d'ordre moral : la technologie est-elle acceptable et ne s'agit-il pas d'une transgression des lois de la nature ? Frewer et al (2011) ont montré que certaines technologies soulèvent des inquiétudes en raison d'effets redoutés possibles et imprévisibles, ou d'une utilisation incontrôlée et non éthique. Une des dimensions importantes de ces débats porte sur le caractère nécessaire (ou non) de la technologie pour la société, ce dernier étant évalué par une balance coût/bénéfice de l'introduction de la technologie. Dans le cas de la viande artificielle, face aux coûts exposés ci-dessus, les bénéfices attendus sont un mal-être animal réduit, une baisse de la production de gaz à effets de serre et la création d'une nouvelle source de protéines (Post 2012). Le jeu en vaut-il la chandelle ? Quel est le véritable statut de ce produit qualifié, par certains, de zombie (Stephens 2010)?

L'autre critère a trait à l'acceptabilité du produit physique mis sur le marché avec tous ses attributs. Comme pour tout produit alimentaire, les consommateurs ne seront pas disposés à faire des compromis en matière de sécurité alimentaire avec la viande artificielle. Les attentes en matière de goût, santé, prix et durabilité devront également être prises en compte. L'accueil que réserveraient les consommateurs à de la viande artificielle n'est pas mesurable aujourd'hui dans la mesure où aucun produit fini n'a été proposé sur le marché (à l'exception du «quorn »). Il y a en effet un fossé important entre la culture in vitro d'une quantité réduite de cellules et la formulation d'un produit mis sur le marché. Il est difficile de se fier aux quelques tests favorables réalisés par des financeurs de ce projet (tels que PETA, «People for the Ethical Treat- ment of Animals ») (Driessen et Korthals 2012). De même, l'évaluation de la qualité de service de ces produits, la durée de conservation notamment, n'est pas possible.

Enfin, l'étude de Rollin et al (2011) a soulevé le rôle de l'information apportée par les médias, des connaissances objective et subjective des consommateurs et de l'étiquetage. L'importance de la couverture médiatique peut être un déterminant de rejet ou d'acceptation par les citoyens-consommateurs. Driessen et Korthals (2012) mentionnent que la viande in vitro a déjà donné lieu à une attention accrue des médias aux Pays-Bas. L'analyse de Goodwin et Shoulders (2013) montre que, jusqu'à présent, les médias ont surtout rappelé aux consommateurs les problèmes de l'élevage conventionnel et les solutions offertes par la viande artificielle.

\section{2 / Résultats d'études auprès des consommateurs-citoyens}

Vanhonacker et al (2013) ont étudié l'intérêt des consommateurs à manger moins de viande dans le contexte d'une alimentation plus durable. La volonté des consommateurs de réduire leur consommation de viande était élevée (72\%). De plus, $73 \%$ ont déclaré leur volonté de consommer des substituts de viande plus écologiques, $45 \%$ des types de viande hybrides (mélanges de protéines d'origines animale et végétale) et $35 \%$ des produits à base de protéines végétales. En revanche, seulement $5 \%$ ont déclaré être prêts à consommer des sources de protéines à base d'insectes.

Les études sur les réactions des consommateurs à la notion de viande in vitro sont encore très rares. Basé sur un sondage exploratoire, Pluhar (2010) a rapporté que la première réaction des consommateurs à la viande artificielle est une répulsion. Dans une autre étude menée dans différents pays européens, Marcu et al (2013) ont constaté que les consommateurs ont mentionné diverses questions et préoccupations telles que la sécurité des produits, leur valeur nutritive et leur prix, ainsi que les procédures technologiques, les incertitudes scientifiques, et finalement les implications sociales, économiques et culturelles.

\section{6 / Comment satisfaire nos besoins en protéines durant les prochaines décennies?}

Un des grands défis du futur sera la sécurité alimentaire et notamment la satisfaction des besoins en protéines. Cet enjeu majeur, combiné aux préoccupations de notre société moderne (défi 
environnemental, souci du bien-être animal, pollution, maladies...), suggèrent des voies de changement dans nos habitudes alimentaires.

Une première voie d'évolution est d'accroître la part des protéines végétales dans l'alimentation humaine aux dépens de la viande. En France, l'ensemble des viandes (issues des ruminants, des porcs et des volailles) représente un peu plus du quart de l'apport protéique. Un courant de pensée se développe pour réduire cette contribution sachant qu'il existe des protéines végétales de qualité dans les légumineuses, les céréales complètes et les produits simili-carnés tels que le tofu. Dans plusieurs pays ou civilisations, le régime alimentaire de base associe des protéines végétales de différentes sources (riz et lentilles en Inde, soja et riz en Chine, maïs et haricots rouges en Amérique du Sud...). Une alternative à la viande est donc l'accroissement de la part des protéines végétales dans la ration alimentaire de l'Homme. Cette stratégie est facile à mettre en œuvre à court ou long terme. Elle se heurte toutefois au désir des consommateurs des pays en voie de développement de consommer davantage de produits carnés au fur et à mesure de l'accroissement de leur revenu (Zhou et al 2012). Toutefois, la rareté ou l'envolée des prix des produits carnés peuvent mettre fin à cette évolution et ainsi favoriser la consommation de protéines végétales. De nombreuses entreprises s'intéressent à la préparation de steaks de protéines végétales afin de satisfaire le souhait des consommateurs pour des produits qui ressembleraient par leur goût et par leur forme à de la viande.

Une deuxième voie d'évolution permettrait de réduire les risques pesant sur l'environnement car certains experts proposent des alternatives à l'élevage intensif: l'élevage à haute valeur environnementale, l'élevage autonome et économe ou encore l'élevage biologique. Ces élevages sont généralement basés sur une forte autonomie alimentaire et, dans le cas des ruminants, sur une forte autonomie fourragère, avec moins d'aliments achetés en dehors des exploitations. L'élevage biologique regroupe un ensemble de pratiques fondées sur des équilibres et des régulations écologiques pour créer un système complet, autonome, viable et socialement vivable (Bouihol 2013). Ces élevages sont moins productifs par hectare ou par travailleur. Ils fournissent globalement moins de viande, celle-ci étant plus coûteuse, mais ce type d'approche réduit les inconvénients des systèmes intensifs.

Une troisième voie d'évolution pourrait venir de la diversification des espèces animales en élevage. En effet, dans de nombreux pays, on trouve des élevages d'espèces moins conventionnelles (rongeurs, reptiles, insectes...) destinés à produire des aliments pour l'Homme. Toutefois, leur consommation se heurte à des problèmes culturels. Ainsi, il ne viendra pas à l'idée du consommateur français de manger des cochons d'Inde comme dans les Andes (Rosenfeld 2008) ou de la viande de rat comme dans certaines régions de Thaïlande ou de Chine. A contrario, le consommateur français surprend par le fait qu'il consomme des cuisses de grenouilles ou des escargots. D'une façon générale, les protéines des produits carnés issus d'oiseaux, de reptiles, de mammifères ou d'insectes présentent un profil en acides aminés proche de la protéine idéale telle que définie par l'Organisation Mondiale de la Santé (OMS, 2007). Par ailleurs, pour environ 2,5 milliards de personnes, principalement en Afrique, en Asie et en Amérique latine, se nourrir d'insectes fait partie du quotidien car il existe plus de 1700 espèces d'insectes comestibles. De fait, il devient de plus en plus envisageable d'utiliser les insectes comme source de nourriture humaine ou animale, comme en témoigne la couverture médiatique importante sur ce sujet (FAO 2013). Il n'en demeure pas moins que la généralisation de ce type d'aliment se heurte pour l'instant à des barrières culturelles. Toutefois, nous n'avons pas les mêmes valeurs alimentaires que nos ancêtres : par exemple, la consommation de viande de chien était répandue dans l'antiquité romaine, la civilisation aztèque et présente en Europe jusqu'au début du XXème siècle. Aujourd'hui, la consommation de viande de chien est encore présente en Asie mais non en Europe tandis que la consommation de viande de cheval diminue fortement dans les pays développés. Comment se comporteront les générations futures, par exemple face à la possibilité de manger des insectes?

Une dernière voie d'évolution consiste à répondre à la demande croissante en prolongeant les progrès de productivité du passé avec un souci d'efficience, c'est-à-dire de meilleure valorisation des intrants grâce à un meilleur fonctionnement digestif et métabolique des animaux. D'une façon générale, l'augmentation de la population mondiale et la croissance rapide des revenus et de l'urbanisation vont continuer à doper la demande en viande d'ici à 2050. Ainsi, pour la FAO (2009), une part croissante de la demande en produits carnés sera couverte par des élevages plus intensifs (et donc plus efficients). Cette voie d'évolution a déjà fait ses preuves : malgré une population qui est passée de 3 milliards en 1960 à 7 milliards en 2011, les famines ont presque disparu et le nombre de malnutris a diminué en pro- portion. Cette évolution a eu pour effet d'augmenter la part des mono- gastriques (porcs et volailles) dans la consommation mondiale de viande, ce qui a été favorable du point de vue de la production de GES. Cette modernisation a été largement basée sur la croissance de l'offre mondiale de céréales et d'oléo-protéagineux. Mais les rendements céréaliers continueront-ils à croître dans les pays où ils sont très inférieurs aux nôtres ? Trouverons-nous suffisamment de nouvelles terres labourables ? La FAO a répondu positivement à ces questions. De plus, cette poursuite de la tendance actuelle apparaît prometteuse en raison de nouveaux outils performants comme, par exemple, la sélection génomique qui améliore de façon spectaculaire l'efficacité de la sélection génétique des animaux (Bidanel et al 2008). Par ailleurs, l'agrandissement de la taille des élevages permet un gain d'efficacité important y compris en France (Charroin et al 2012). La modernisation globale de l'élevage au niveau mondial a donc encore un avenir intéressant. Cependant, d'autres experts, dont ceux qui font la promotion de la viande artificielle, considèrent sans base scientifique que nous sommes arrivés au bout des limites physiologiques ou techniques d'amélioration des performances des élevages.

Les quatre voies d'évolution possibles que nous venons de décrire (consommer davantage de protéines végétales, consommer d'autres sources de protéines animales, développer de nouvelles pratiques d'élevage, poursuivre la modernisation des élevages) sont des alternatives sérieuses, non exclusives, voire complémentaires au développement de la viande artificielle. Elles présentent toutes l'avantage de pouvoir être mises en œuvre à court terme, contrairement à la production de viande artificielle. Des travaux de recherche de tous ordres sont néanmoins nécessaires pour rendre ces solutions plus durables en termes économique et sociétal. Les deux propositions qui semblent atténuer le mal-être supposé des animaux et l'empreinte carbone sont $i$ ) la promotion de l'incorporation croissante de protéines végétales dans l'alimentation humaine surtout dans les pays développés et ii) la production de viande artificielle, la première solution étant plus facile et évidente que la seconde. Le développement de nouvelles pratiques respectueuses de l'environnement pour un élevage durable favorisant un élevage autonome et économe font déjà partie des priorités de grands instituts de recherche comme l'INRA en France (Dedieu et al 2008) ou l'USDA aux Etats-Unis (Brandebourg et al 2013). 


\section{Conclusion}

L'élevage est aujourd'hui l'objet de questionnements importants que ce soit sur le plan économique, environnemental ou sociétal. Satisfaire la demande mondiale croissante en viande et plus généralement en protéines, atténuer les conséquences de l'élevage sur le réchauffement climatique et l'environnement, et enfin répondre aux attentes sociétales en matière de qualité des produits et de bien-être animal sont des enjeux majeurs qui interrogent la recherche agronomique. Plusieurs voies de recherche sont explorées pour répondre à ces enjeux comme, par exemple, diversifier les sources de protéines végétales ou animales dans l'alimentation humaine, rééquilibrer notre ration alimentaire au profit des protéines végétales, ou encore développer des systèmes d'élevage innovants qui privilégient l'efficience économique et biologique et/ou la protection de l'environnement et le respect du bien-être animal.

La question posée - « La viande du futur sera-t-elle produite in vitro ?»telle que reprise par les médias nous apparaît donc trop restrictive et inadaptée pour répondre rapidement aux enjeux du futur. La production de viande artificielle n'est qu'une solution parmi d'autres face à ces enjeux et les processus de production sont encore embryonnaires. Cette proposition doit être évaluée par rapport aux autres solutions proposées, non seulement sur les plans scientifique et technique, mais aussi en termes économique, environnemental et sociétal.

Du point de vue technique, il y a un consensus, y compris parmi les scientifiques favorables à la production de viande artificielle, pour dire que cette technologie n'est pas encore suffisamment avancée pour être mise en œuvre rapidement. Une, voire plusieurs dizaines d'années de recherches sont encore nécessaires alors que les questions posées par l'élevage sont à résoudre plus rapidement. Du point de vue économique, la production de viande artificielle est encore bien trop onéreuse pour être développée en routine alors que les autres solutions explorées le sont beaucoup moins et peuvent être mises en œuvre plus rapidement. Du point de vue environnemental, la production de viande artificielle présente certains avantages, mais il est prématuré d'estimer son empreinte carbone du fait que les procédés industriels qui seraient retenus sont incertains. Enfin, si sur le plan sociétal, la production de viande artificielle contribuerait, de fait, à réduire le malêtre supposé des animaux d'élevage, son acceptation par les consommateurs est loin d'être prouvée. On peut penser que la réaction initiale vis-à-vis de ce type de produit serait majoritairement la répulsion et qu'il faudrait plusieurs générations pour que la viande artificielle trouve sa place voire s'impose éventuellement sur le marché.

Pour répondre aux enjeux auxquels doit faire face l'élevage, des solutions plus évidentes que la production de viande artificielle sont possibles. Il nous paraît plus raisonnable de promouvoir un meilleur équilibre des protéines végétales et animales dans la ration de l'Homme. Rééquilibrer la ration alimentaire, diversifier nos sources de protéines végétales et animales, ou encore produire notre viande à l'aide de systèmes d'élevage innovants nous semblent en effet des solutions efficaces, moins onéreuses, plus rapides, plus faciles et réalistes à mettre en œuvre.

\section{Références}

Alary V., Duteurtre G., Faye B., 2011. Elevages et sociétés : les rôles multiples de l'élevage dans les pays tropicaux. In : Numéro spécial, Elevage en régions chaudes. Coulon J.B., Lecomte P., Boval M., Perez J.M. (Eds). INRA Prod. Anim., 24, 145-156.

Asgar M.A., Fazilah A., Huda N., Bhat R., Karim A.A., 2010. Non Meat Protein Alternatives as Meat Extenders and Meat Analogs. Compr. Rev. Food. Sci. Food Saf., 9, 513-529.

Bauchart D., Gandemer G., 2010. Qualité nutritionnelle des viandes et abats de bovin. In : Muscle et Viande de Ruminants. Bauchart D., Picard B. (Eds). Editions Quae, Paris, France, 115-130.

Bauchart D., Thomas A., 2010. Facteurs d'élevage et valeur santé des acides gras des viandes. In : Muscle et Viande de Ruminants. Bauchart D., Picard B. (Eds). Editions Quae, Paris, France, 131-142.

Benjaminson M.A., Gilchriest J.A., Lorenz M., 2002. In vitro edible muscle protein production system (MPPS): stage 1, fish. Acta Astronaut., 51, 879-889.

Bhat Z.F., Bhat H., 2011a. Animal-free meat biofabrication. Am. J. Food Technol., 6, 441459.

Bhat Z.F., Bhat H., 2011b. Tissue engineered meat- Future meat. J. Stored Products Postharvest Res., 2, 1-10.

Bidanel J.P., Boichard D., Chevalet C., 2008. De la génétique à la génomique. In : Numéro spécial, 20 ans de recherches en pro- ductions animales à l'INRA. Charley B., Herpin P., Perez J.M. (Eds). INRA Prod. Anim., 21, 15-32.

Bouihol M., 2013. Dans : "Productions Animales de $\mathrm{A}$ à $\mathrm{Z}$ », à paraître aux Editions Lavoisier.

Brandebourg T.D., Wolfe D.F., Foradori C.D., 2013. U.S. beef industry: a sustainable success story, challenges and priorities. J. Fisheries Livest. Prod., 1, 2. http://dx.doi.org/ $\underline{10.4172 / \text { jflp. } 1000102}$

Cassar-Malek I., Langlois N., Picard B. Geay Y., 1999. Regulation of bovine satellite cell proliferation and differentiation by insulin and triiodothyronine. Domest. Anim. Endocrin., 17, 373-388.

Charroin T., Veysset P., Devienne S., Fromont J.L., Palazon R., Ferrand M., 2012. Productivité du travail et économie en élevages d'herbivores : définition des concepts, analyse et enjeux. In : Numéro spécial, Travail en élevage. Hostiou N., Dedieu B., Baumont R. (Eds). INRA Prod. Anim., 5, 193-210.

Churchill W.S., 1932. Thoughts and adventures. London, Thornton Butterworth, 18p.

Code d'usages en matière d'hygiène pour la viande - CAC/RCP 58-2005 Codex alimentarius, $\mathrm{p} 55$.

Corson M.S., Doreau M., 2013. Evaluation de l'utilisation de l'eau en élevage. INRA Prod. Anim., 26, 239-248.

Datar I., Betti M., 2010. Possibilities for an in vitro meat production system. Innov. Food Sci. Emerg. Technol., 11, 13-22.
Dedieu B., Faverdin P., Dourmad J.Y., Gibon A., 2008. Système d'élevage, un concept pour raisonner les transformations de l'élevage. In : Numéro spécial, 20 ans de recherches en productions animales à l'INRA. Charley B., Herpin P., Perez J.M. (Eds). INRA Prod. Anim., 21, 45-58.

Denoyelle C., 2008. Les viandes, une question de définition. Cah. Nutr. Diet., 43, (Horssérie), 1S7-1S10.

Dodson M.V., McFarland D.C., Martin E.L., Brannon M.A., 1986. Isolation of satellite cells from ovine skeletal muscles. Method. Cell Sci., $10,233-237$

Dodson M.V., Martin E.L., Brannon M.A., Mathison B.A., McFarland D.C., 1987. Optimization of bovine satellite cell-derived myotube formation in vitro. Tissue Cell, 19, 159-166.

Dollé J.B., Agabriel J., Peyraud J.L., Faverdin P., Manneville V., Raison C., Gac A., Le Gall A., 2011. Les gaz à effet de serre en élevage bovin : évaluation et leviers d'action. In : Gaz à effet de serre en élevage bovin : le méthane. Doreau M., Baumont R., Perez J.M. (Eds). Dossier INRA Prod. Anim., 24, 415432 .

Driessen C., Korthals M., 2012. Pig towers and in vitro meat: disclosing moral worlds by design. Soc. Stud. Sci., 42, 797-820.

École de technologie supérieure de Montréal. 2012. 3D bio-printing : imprimer des muscles et des organes. http://etsinnovation.wordpress. com $/ 2012 / 03 / 05 / 3$ d-bio-printing-imprimerdes-muscles-et-des-organes/ 
Esnouf C., Russel M., Bricas N. (coords), 2011. Pour une alimentation durable. Réflexion stratégique duALIn. Editions Quae, Paris, France, 288p.

Food and agriculture organization of the United Nations (FAO), 2009. «La situation mondiale de l'alimentation et de l'agriculture : le point sur l'élevage. ». http://www.fao.org/ docrep/012/i0680f/i0680f.pdf

Food and agriculture organization of the United Nations (FAO), 2013, Les insectes comestibles issus de la forêt. http://www.fao. org/forestry/edibleinsects/fr/

Frewer L.J., Bergmann K., Brennan M., Lion R., Meertens R., Rowe G., Siegrist M., Vereijken C., 2011. Consumer response to novel agri-food technologies: implications for predicting consumer acceptance of emerging food technologies. Trends Food Sci. Tech., 22, 422-456

GIEC, 2007. Bilan 2007 des changements climatiques. Contribution des Groupes de travail I, II et III au quatrième rapport d'évaluation du groupe d'experts intergouvernemental sur l'évolution du climat. GIEC, Genève, Suisse, 103 p.

Godon B., 1996. Protéines végétales. Collection Sciences et Techniques Agroalimentaires. Editions Tec \& Doc Lavoisier, Paris, 666p.

Halász A., Lásztity R., 1991. Use of yeast biomass in food production. CRC Press Inc.

Hébel P., 2007. Comportements et consommations alimentaires des français, Editions Tec \& Doc Lavoisier, Paris, France, D-00-31.

Hopkins P.D., Dacey A., 2008. Vegetarian meat: Could technology save animals and satisfy meat eaters? J. Agr. Environ. Ethic., 21, 579-596.

Langelaan M.L.P., Boonen K.J.M., Polak R. B., Baaijens F.P.T., Post M.J., van der Schaft D.W.J., 2010. Meet the new meat: tissue engineered skeletal muscle. Trends Food Sci. Tech. 21, 59-66.

Leip A., Weiss F., Wassenaar T., Perez I., Fellmann T. Loudjani P. Tubiello F., Grandgirard D., Monni S., Biala K., 2010. Evaluation of the livestock sector's contribution to the EU greenhouse gas emissions (GGELS)
- final report. Eur. Com., Joint Research Centre, $323 \mathrm{p}$

Lestel D., 2011. Apologie du carnivore Editions Fayard, Paris, France, 142p.

Marcu A., Barnett J., Gaspar R., Rutsaert P., Seibt B., Verbeke W., 2013. Asking questions about synthetic meat: the role of information seeking in making sense of a novel food technology. FoodRisC Working Paper.

McFarland D.C., Doumit M.E., Minshall R.D., 1988. The turkey myogenic satellite cell: Optimization of in vitro proliferation and differentiation. Tissue Cell, 20, 899-908.

Organisation mondiale de la santé (WHO), 2007. «Protein quality evaluation in human diets. ") Report of a joint FAO/WHO Expert. http://www.who.int/fr/

Picard B., Lefaucheur L., Berri C., Duclos M., 2002. Muscle fibre ontogenesis in farm animal species. Reprod. Nutr. Dev., 42, $415-$ 431

Pluhar E., 2010. Meat and morality: alternatives to factory farming. J. Agr. Environ. Ethic. $23,455-468$.

Post M.J., 2012. Cultured meat from stem cells: Challenges and prospects. Meat Sci., 92, 297-301.

Purwanti N., Van der Goot A.J., Boom R., Vereijken J., 2010. New directions towards structure formation and stability of protein-rich foods from globular proteins. Trends Food Sci. Tech., 21, 85-94.

Rémond D., Peyron M.A., Savary-Auzeloux I., 2010. Viande et nutrition protéique. In Muscle et viande de ruminant. Bauchart D. Picard B. (Eds). Editions Quae, collections synthèses, 255-266

Ridoutt B.G., Sanguansri P., Freer M. Harper G.S., 2012. Water footprint of livestock: comparison of six geographically defined beef production systems. Int. J. Life Cycle Assess., 17, 165-175.

Rollin F., Kennedy J., Wills J., 2011 Consumer response to new food technologies. Trends Food Sci. Tech., 22, 99-111.

Rosenfeld S.A., 2008. Delicious guinea pigs: seasonality studies and the use of fat in the pre-Columbian Andean diet. Quaternary Int., $180,127-134$

Sen A.K., 1981. Poverty and famines: an essay on entitlement and deprivation, OUP Oxford, Clarendon Press, 272p.

Stephens N., 2010. In vitro meat: zombies on the menus. Scripted, 7, 394-401.

Tuomisto H.L., Roy A.G., 2012. Could cultured meat reduce environmental impact of agriculture in Europe? In: Proc. $8^{\text {th }}$ Conf. LCA in the Agri-Food sector, October $1^{\text {st }}-4^{\text {th }} 2012$, Saint-Malo, France, 615-619.

Tuomisto H.L., Teixeira de Mattos M.J., 2011. Environmental impacts of cultured meat production. Environ. Sci. Technol., 45, 61176123.

Van Eelen W.F., van Kooten W.J., Westerhof W., 1999. WO/1999/031223: Industrial production of meat from in vitro cell cultures. http://patentscope.wipo.int/search/en/WO1999 031223 No. WO/1999/031223, The Netherlands.

Vanhonacker F., Van Loo E.J., Gellynck X., Verbeke W., 2013. Flemish consumer attitudes towards more sustainable food choices. Appetite, $62,7-16$

Verbeke W., 2011. Consumer attitudes and communication challenges for agro-food technologies. Agro-Food Industry hi-tech, 22, 34-36.

Welin S., van der Weele C., 2012. Cultured meat: will it separate us from nature? In: Potthast T., Meisch S. (Eds). Climate change and sustainable development (Eursafe 2012), Wageningen Academic Publishers, The Netherlands.

Wilschut K.J., Jaksani S., Van Den Dolder J., Haagsman H.P., Roelen B.A.J., 2008. Isolation and characterization of porcine adult musclederived progenitor cells. J. Cell. Biochem., $105,1228-1239$

Yablonka-Reuveni Z., Quinn L.S., Nameroff M., 1987. Isolation and clonal analysis of satellite cells from chicken pectoralis muscle. Dev. Biol., 119, 252-259.

Zhou G., Zhang W., Xu X., 2012. China's meat industry revolution: Challenges and opportunities for the future. Meat Sci., 92, 188196.

\section{Résumé}

La production de viande artificielle par culture de cellules est proposée par certains scientifiques comme une des solutions pour répondre aux grands enjeux de l'élevage : $i$ ) réduire le mal-être supposé des animaux dans les élevages modernes, voire ne pas tuer les animaux pour les manger, ii) réduire la possible dégradation de l'environnement par l'élevage et iii) réduire la faim dans le monde en augmentant le niveau des ressources protéiques alimentaires. La viande artificielle supprimerait en effet le mal-être supposé des animaux lié à l'élevage et permettrait de ne pas abattre les animaux pour les manger. L'impact environnemental de la viande artificielle est difficile à évaluer en l'absence de données sur le fonctionnement d'une usine de production. La viande artificielle présenterait toutefois un intérêt modéré pour réduire les gaz à effet de serre et la pollution par les nitrates, un intérêt limité quant à l'utilisation des énergies fossiles, voire très limité pour limiter les besoins en eau, mais elle libérerait des terres cultivables. Elle entraînerait probablement dans l'eau des résidus de molécules de synthèse. De nombreux experts estiment que les causes de la malnutrition actuelle de certaines populations sont multiples et ne sont pas directement liées à un manque de ressources alimentaires. Bien que la culture de cellules soit couramment pratiquée en laboratoire, il existe des verrous techniques importants à lever pour une production à grande échelle, tels que le coût rédhibitoire des technologies actuelles et le manque de ressemblance du produit obtenu à de la viande issue d'animaux. Sur le plan nutritionnel, la viande artificielle ne présente pas d'avantage particulier par rapport à un autre aliment élaboré à partir de l'ensemble des nutriments nécessaires à sa production. Les critères d'acceptabilité de la viande artificielle renvoient, d'une part, à des questions d'ordre moral ou éthique concernant la technologie et les inquiétudes qu'elle soulève, et d'autre part, à des considérations classiques relatives aux produits alimentaires (prix, qualité, naturalité...). Par le passé, les expériences de substitution des protéines animales par des produits analogues ont échoué en raison, notamment, de contraintes économiques, du temps nécessaire pour l'éventuelle acceptation des produits par les consommateurs et pour la délivrance des autorisations de mise sur le marché. Face aux questionnements importants concernant l'élevage, la production de viande artificielle ne présente pas aujourd'hui d'avantages majeurs par comparaison à la viande naturelle ou à d'autres alternatives possibles telles que rééquilibrer notre alimentation en diversifiant les sources de protéines végétales et animales, ou encore développer des systèmes d'élevage plus respectueux des animaux et de l'environnement. 


\begin{abstract}
Will meat be produced in vitro in the future?

The production of artificial meat by cell culture is suggested by some scientists as one solution to address the major challenges facing our society: (i) reducing potential discomfort of animals on modern farms or avoiding killing animals to eat them (ii) reducing potential environmental degradation by livestock and (iii) reducing world hunger by increasing protein resources. Artificial meat would indeed eliminate any animal "suffering" in farming systems and would avoid the slaughtering of animals to eat them. The environmental impact of artificial meat is difficult to evaluate due to the absence of references on production units. However, it may have a moderate interest in reducing greenhouse gas emissions and pollution by nitrates, a limited interest for decreasing fossil fuel use or a very limited interest concerning water use, but it would make more land available. It may result in the presence of organic molecule residues in water. Nevertheless, many experts believe that the causes of the current malnutrition of some human populations are diverse, and not directly related to a lack of food resources. Although cell culture can be usually performed in laboratories, there are significant major technical difficulties to move towards a large-scale production as the prohibitive cost of current technologies and the lack of similarity of the obtained product with meat from animals. From a nutritional point of view, artificial meat has no particular advantage compared to another type of food made from all nutrients necessary for its production. The criteria for acceptability of artificial meat refer, first, to moral or ethical concerns about the technology and the worries it raises, and secondly, to usual food product concerns (price, quality, naturality, etc.). In the past, attempts to substitute animal proteins with similar products have failed due to economic constraints, the time required for potential product acceptance by consumers and permission to place the products on the market by public authorities. In conclusion, given the important challenges facing livestock, production of artificial meat does not present any major advantage compared to natural meat or to other options such as balancing human food supply by more diverse sources of plant and animal proteins, or developing friendly farming systems for animals and the environment. Technical, economic and social constraints, including uncertain acceptance by consumers of artificial foods, are indeed major limitations to the development of artificial meat.
\end{abstract}

HOCQUETTE J.-F., MAINSANT P., DAUDIN J.-D., CASSAR-MALEK I., RÉMOND D., DOREAU M., SANS P., BAUCHART D., AGABRIEL J., VERBEKE W., PICARD B., 2013. La viande du futur sera-t-elle produite in vitro ? INRA Prod. Anim., 26, 4, 363-374. 